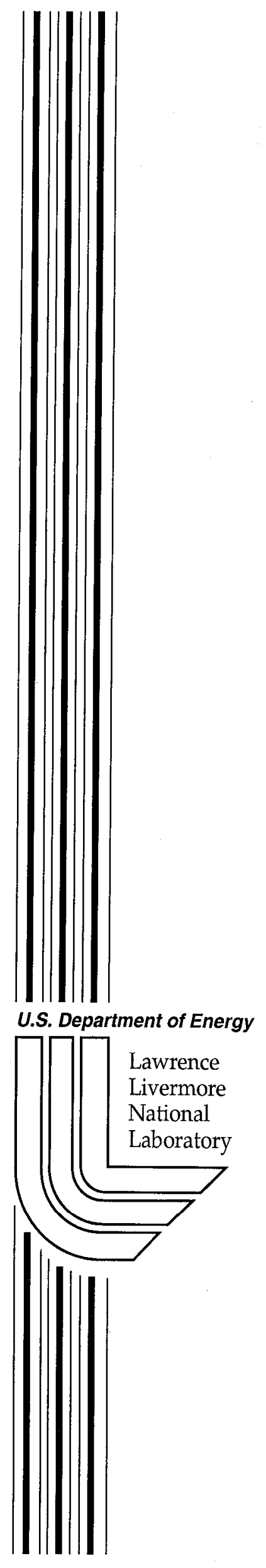

UCRL-ID-137358

\title{
Hydrodynamic Expansion of Pellicles Caused by e-Beam Heating
}

D. D.-M. Ho

February 1, 2000 



\section{DISCLAIMER}

This document was prepared as an account of work sponsored by an agency of the United States Government. Neither the United States Government nor the University of California nor any of their employees, makes any warranty, express or implied, or assumes any legal liability or responsibility for the accuracy, completeness, or usefulness of any information, apparatus, product, or process disclosed, or represents that its use would not infringe privately owned rights. Reference herein to any specific commercial product, process, or service by trade name, trademark, manufacturer, or otherwise, does not necessarily constitute or imply its endorsement, recommendation, or favoring by the United States Government or the University of California. The views and opinions of authors expressed herein do not necessarily state or reflect those of the United States Government or the University of California, and shall not be used for advertising or product endorsement purposes.

Work performed under the auspices of the U. S. Department of Energy by the University of California Lawrence Livermore National Laboratory under Contract W-7405-Eng-48.

This report has been reproduced directly from the best available copy.

Available to DOE and DOE contractors from the Office of Scientific and Technical Information

P.O. Box 62, Oak Ridge, TN 37831

Prices available from (423) 576-8401 http://apollo.osti.gov/bridge/

Available to the public from the National Technical Information Service

U.S. Department of Commerce 5285 Port Royal Rd., Springfield, VA 22161 http://www.ntis.gov/

\section{OR}

Lawrence Livermore National Laboratory Technical Information Department's Digital Library http://www.llnl.gov/tid/Library.html 


\title{
Hydrodynamic Expansion of Pellicles Caused by e-Beam Heating
}

\author{
Darwin D.-M. Ho
}

\section{Summary}

Placing a pellicle in front of a $\mathrm{x}$-ray converter target for radiographic applications can confine the backstreaming ions and target plasma to a shorter channel so that the cumulative effect on e-beam focusing is reduced. The pellicle is subject to heating by ebeam since the pellicle is placed upstream of the target. The calculation of the hydrodynamic expansion, caused by the heating, using the radiation hydrodynamics code LASNEX is presented in this report. Calculations show that mylar pellicles disintegrate at the end of a multi-pulse intense e-beam while beryllium and carbon pellicles remain intact. The expansions for the kapton-carbon multi-layered targets are also examined. Hydrodynamic expansions for pellicles with various e-beam spot radii are calculated for DARHT-II beam parameters. All the simulation results indicate that the backstreaming ions can be stopped.

\section{Description of the LASNEX Simulations and Discussion of the Results}

We have performed LASNEX simulations for pellicles heated by e-beams. The pellicles have a thickness of $5 \mu \mathrm{m}$. The pellicles can be fabricated from various materials, e.g., mylar, beryllium, carbon, and kapton. The pellicles can be either single, double, or triple layer made of different materials. The simulations are performed with parameters for the DARHT-II multi-pulse beams. In the simulations, the material strength of the pellicle is represented by a negative pressure in the eos table.

The amount of energy deposited in the pellicle by the e-beam is calculated by Jim McCormick using the Monte Carlo code. The values of the energy deposited in various pellicle materials with thickness of $5 \mu \mathrm{m}$ are listed in the following table.

\begin{tabular}{|l|l|l|}
\hline $\begin{array}{l}\text { Pellicle } \\
\text { material }\end{array}$ & $\begin{array}{l}\text { Electron } \\
\text { energy (MeV) }\end{array}$ & $\begin{array}{l}\text { Energy deposited } \\
\text { (MeV/electron) }\end{array}$ \\
\hline Mylar & 6.0 & $1.0 \mathrm{e}-3$ \\
& 20.0 & $9.9 \mathrm{e}-4$ \\
\hline Beryllium & 6.0 & $1.13 \mathrm{e}-3$ \\
& 20.0 & $1.10 \mathrm{e}-3$ \\
\hline C & 1.0 & $1.62 \mathrm{e}-3$ \\
& 2.0 & $1.54 \mathrm{e}-3$ \\
& 6.0 & $1.53 \mathrm{e}-3$ \\
& 200 & $15 \mathrm{e}-3$ \\
\hline Kapton & 6.0 & $9.9 \mathrm{e}-4$ \\
& 20.0 & $9.8 \mathrm{e}-4$ \\
\hline
\end{tabular}




\section{DARTH-II Beam Parameters}

The multi-pulse beam for DARTH-II consists of three pre-pulses and a main pulse. Each pulse is separated by a time interval of $600 \mathrm{~ns}$ and the total length of the entire pulse train is about $2.02 \mu \mathrm{s}$. The first two pre-pulses are identical. The total pulse length for each of these pulses is $26 \mathrm{~ns}$ with $5 \mathrm{~ns}$ for the rise and $5 \mathrm{~ns}$ for the fall time. The third pulse has a total pulse length of $44 \mathrm{~ns}$ with the same rise and fall time as the previous pulses. The last pulse has a pulse length of $130 \mathrm{~ns}$ with the same raise and fall time. The current is $2 \mathrm{kA}$ for all the pulses and the electron energy is $20 \mathrm{MeV}$. The total energy delivered by the pulse train is about $9 \mathrm{~kJ}$. The thermal conductivity for the various materials used in the simulations are obtained from Ref. 1 . In all the simulations reported in this memo, the maximum temperature reached in the pellicle is sufficiently low that no ionization of the pellicle material is observed.

\section{Hydrodynamic Simulations}

We now discuss the hydrodynamic behavior of various pellicles made of different materials.

1) Mylar pellicle (room temperature density $\rho=1.39 \mathrm{~g} / \mathrm{cm}^{3}$, and composition by fraction of number density --- $0.364 \mathrm{H}, 0.454 \mathrm{C}, 0.182 \mathrm{O}$ )

The initial mesh configuration of the five-micron thick mylar pellicle used for LASNEX simulations is shown in Fig. 1a. The energy deposited in the mylar pellicle vs time is shown in Fig. 2. The total energy deposited into the pellicle is about $0.6 \mathrm{~J}$. For the case with e-beam FWHM spot size of $6 \mathrm{~mm}$, the temperature and density vs time plots for the location at the center of the pellicle are shown in Figs. $3 \mathrm{a}$ and $3 \mathrm{~b}$, respectively. As shown in Fig. 3, at the end of the final pulse at $2.02 \mu \mathrm{s}$, the density at the center of the pellicle drops to about $1.05 \mathrm{~g} / \mathrm{cm}^{3}$ and the temperature reaches about $230^{\circ} \mathrm{C}$, which is around the boiling point for mylar. (The melting temperature for mylar depends on the material density and temperature. For example, in room temperature of $25^{\circ} \mathrm{C}$ and solid density, the melting temperature $T_{m} \approx 450^{\circ} \mathrm{C}$. As the temperature increases, the solid expands. At $\mathrm{T}=240^{\circ} \mathrm{C}$ with $\rho=1.05 \mathrm{~g} / \mathrm{cm}^{3}, \mathrm{~T}_{\mathrm{m}}$ drops to about $230^{\circ} \mathrm{C}$.) The configuration of the pellicle at $2.05 \mu \mathrm{s}$ is shown in Fig. $1 \mathrm{~b}$ which shows the pellicle remains intact at the end of the mult-pulse despite of the thermal expansion.

However, if the FWHM spot size is reduced to $3 \mathrm{~mm}$, then the pellicle starts to disintegrate during the final pulse. The temperature and density vs time plots, at the center of the pellicle, along the axis are shown in Fig. $4 \mathrm{a}$ and $4 \mathrm{~b}$, respectively. Figure $4 a$ shows that the maximum temperature does not exceed $350^{\circ} \mathrm{C}$ since at this temperature, the pellicle starts to expand rapidly and the expansion brings down the 
material temperature. The configuration of the pellicle during the final pulse at $\mathrm{t}=$ $1.9,1.95$, and $2.02 \mu$ s are shown in Figs. 5a, 5b, and 5c, respectively.

Although the pellicle expands rapidly during the final pulse, the value of $\rho r$ (i.e., $\int \rho d z$ ) along the axis remains essentially unchanged. Therefore, the hydro-expansion should have almost no effect as far as ion stopping is concerned.

2) Beryllium pellicle (room temperature density $\rho=1.858 \mathrm{~g} / \mathrm{cm}^{3}$ )

The total energy deposited into the beryllium pellicle is about $0.66 \mathrm{~J}$. For the case with spot size of $3 \mathrm{~mm}$, the density at the center of the pellicle drops to about 1.7 $\mathrm{g} / \mathrm{cm}^{3}$ and the temperature reaches about $1700^{\circ} \mathrm{C}$ at the end of the final pulse at 2.02 $\mu \mathrm{s}$. This temperature is below the boiling temperature of about $2500^{\circ} \mathrm{C}$ for beryllium and the pellicle remains intact at the end of the pulse. The temperature and density vs time plots, at the center of the pellicle, are shown in Fig. $6 \mathrm{a}$ and $6 \mathrm{~b}$, respectively. The final temperature in the beryllium pellicle is substantially higher than that for mylar pellicle. This is because beryllium has a much lower specific heat than mylar.

3) Carbon pellicle (room temperature density $\rho=2.25 \mathrm{~g} / \mathrm{cm}^{3}$ )

The total energy deposited into the carbon pellicle is about $0.9 \mathrm{~J}$. For the case with spot size of $3 \mathrm{~mm}$, the density at the center of the pellicle drops to about $1.9 \mathrm{~g} / \mathrm{cm}^{3}$ and the temperature reaches about $2300^{\circ} \mathrm{C}$ at the end of the pulse. This temperature is below the boiling temperature of about $4800^{\circ} \mathrm{C}$ for carbon at $\rho=1.9 \mathrm{~g} / \mathrm{cm}^{3}$ and the pellicle remains intact at the end of the pulse.

4) Kapton-carbon " $k-c$ " multi-layered pellicles (kapton room temperature density $\rho=$ $1.4 \mathrm{~g} / \mathrm{cm}^{3}$ )

There are concerns that carbon pellicles with thickness of $5 \mu \mathrm{m}$ may be difficult to fabricate. One way to get around this difficulty is to coat carbon on a kapton thin film.

The initial mesh configuration of the k-c pellicle is shown in Fig. 7. The kapton and carbon layers have equal thickness of $5 \mu \mathrm{m}$. The total energy deposited into this layered pellicle is about $1.5 \mathrm{~J}$. The maximum temperatures inside the kapton and carbon layers reach about 2300 and $600^{\circ} \mathrm{C}$, respectively. The carbon temperature is below the boiling but the kapton temperature has reached the boiling point and the kapton layer starts to expand rapidly during the final pulse. The configuration of the pellicle at the end of the pulse at $2.02 \mu \mathrm{s}$ is shown in Fig. 8a and the corresponding density profile along the axis is shown in Fig. 8b. Although the carbon layer is being pushed to the right by the expansion of the kapton layer, the carbon layer remains intact. 
5) Kapton-carbon-kapton " $k$-c-k" multi-layered pellicles

In this configuration, the kapton films are placed on both sides of the carbon pellicle. The initial mesh configuration of the $\mathrm{k}-\mathrm{c}-\mathrm{k}$ pellicle is shown in Fig. 9a. The kapton and carbon layers have equal thickness of $5 \mu \mathrm{m}$. The total energy deposited into this layered pellicle is about 2.1 J. The maximum temperatures inside the layers are similar to those in the k-c pellicle. As shown in Fig. 9b, the carbon layer remains intact at the end of the pulse and the position remains stationary since there are kapton layers on both sides of the carbon layer.

\section{Conclusion}

Simulations show that all the pellicles, except for the one made of mylar, remain intact at the end of the multi-pulse exposure. Despite there is rapid hydro-expansion of the mylar pellicle, the $p r$ is essentially constant. Therefore, all the pellicles studied here should be able to stop backstreaming ions. However, electron scattering is material dependent. Therefore, an additional consideration for choosing the right material is to pick the material that can minimize the electron scattering.

\section{Reference:}

1) Thermal Properties of Materials: The TPRC Data Series, IFI/Plenum, New YorkWashington, 1970. 
$t=0 \mu s$

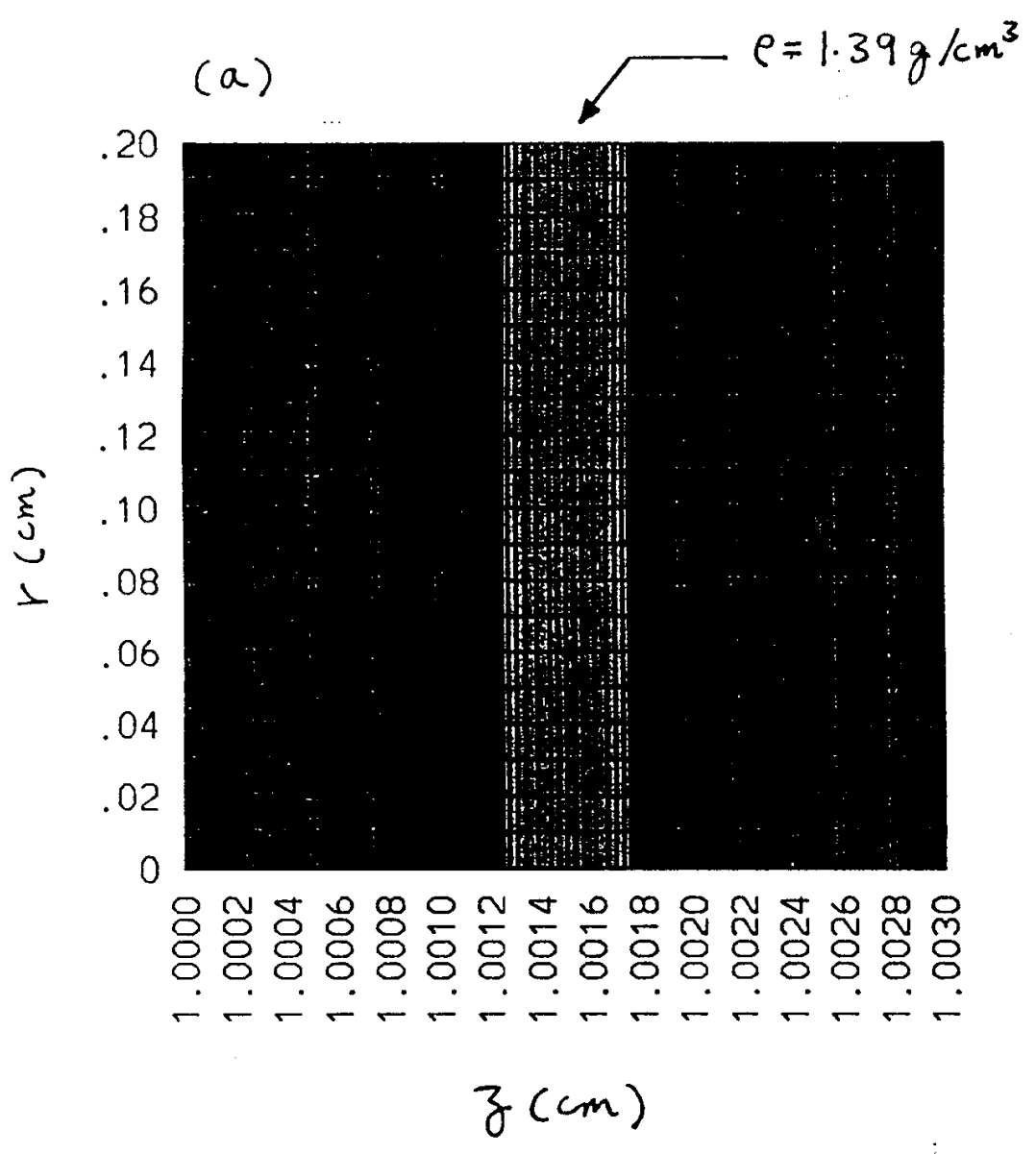

$t=2.02 \mathrm{~ms}$

(b)

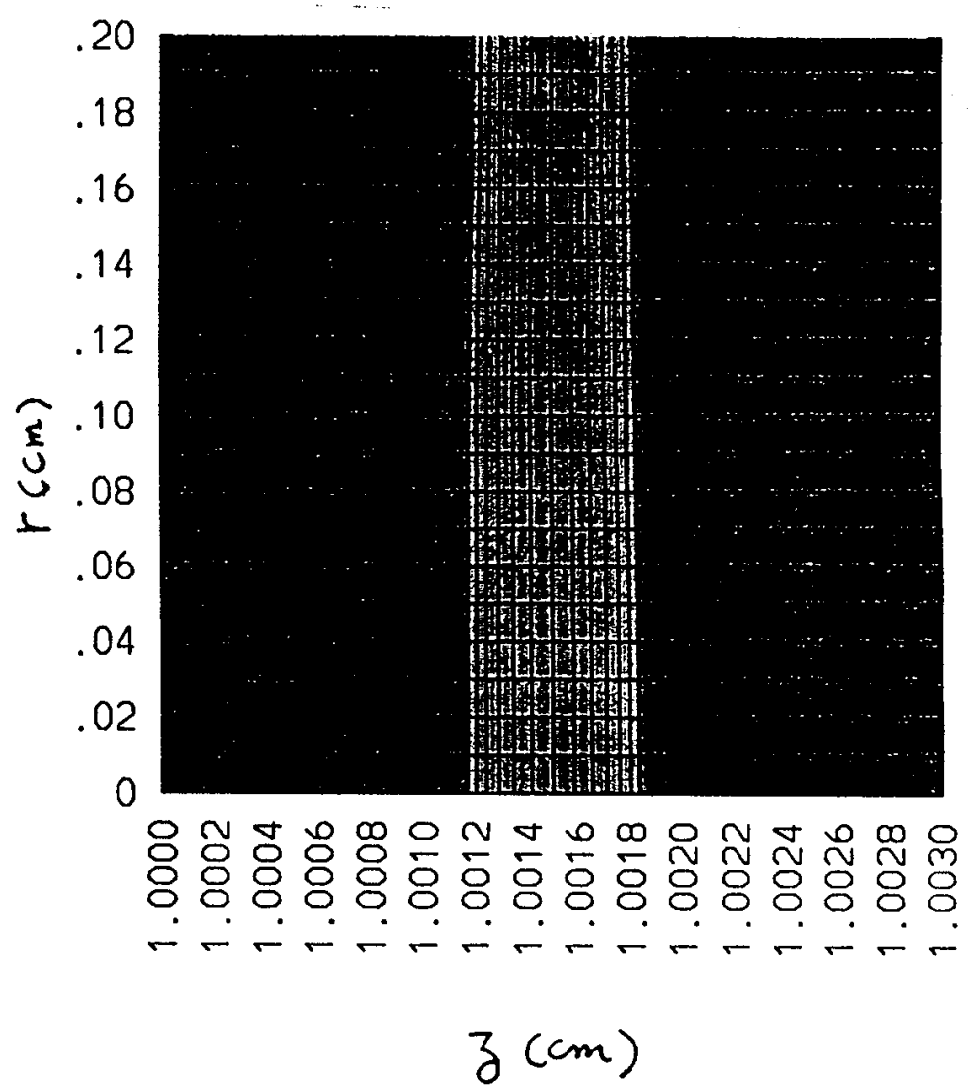

Fig. 1 Mesh configuration for mylar pellicle 


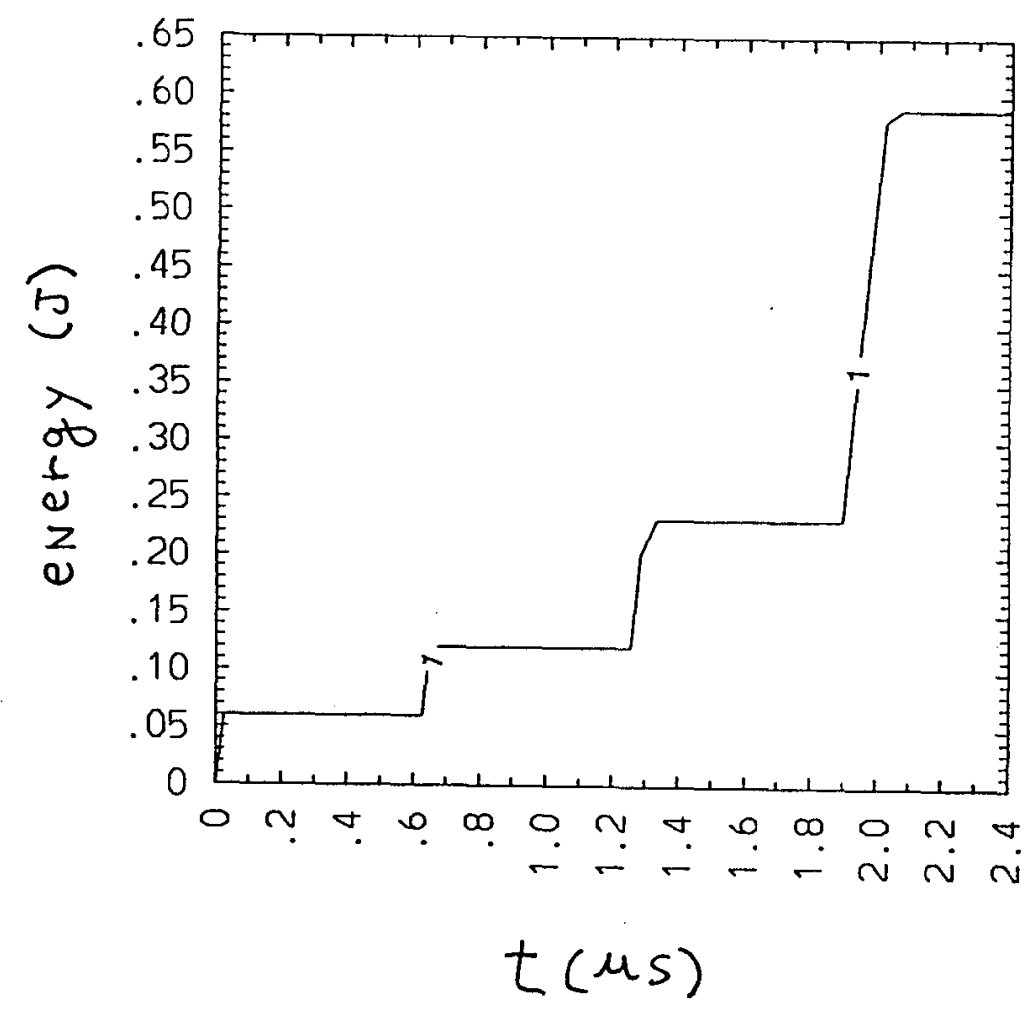

Fig 2. Energy deposited in mylar pellicle
vs time 
Mylar Pellide

$e$-beam FWHM spot size $=6 \mathrm{~mm}$

(a)

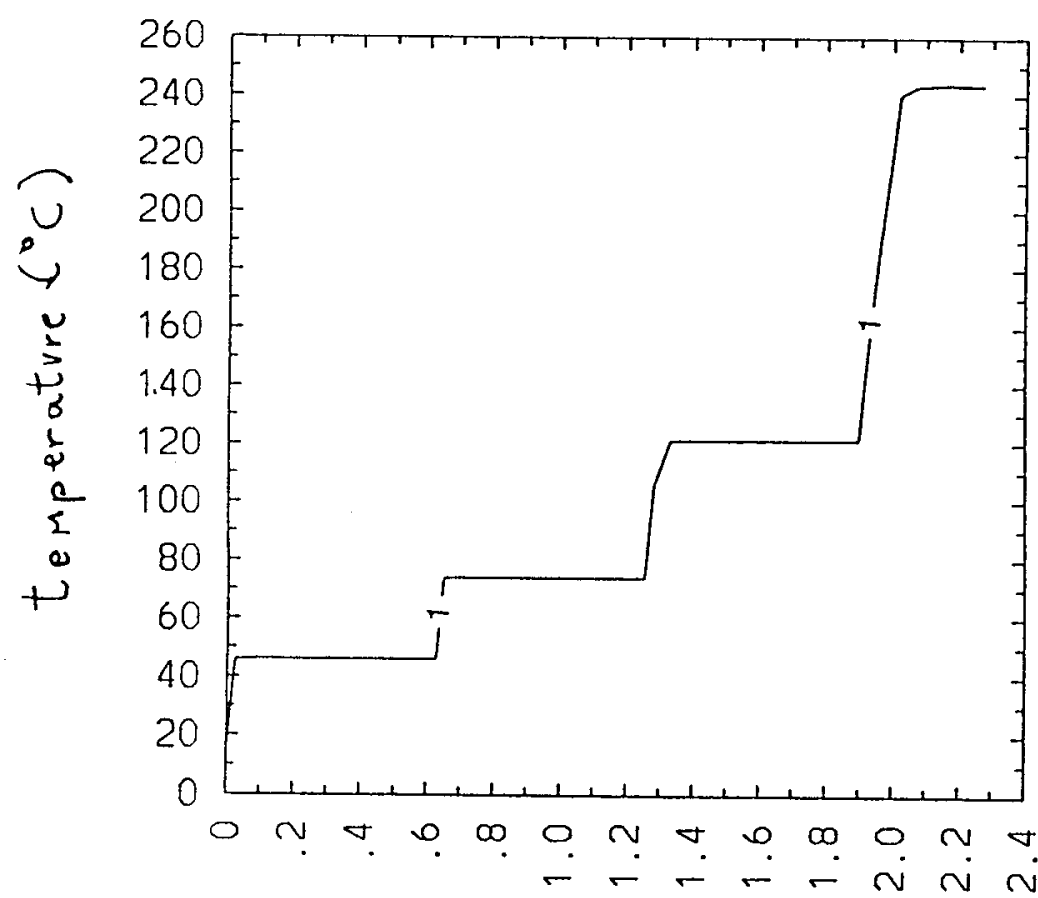

$t$ (us) (b)

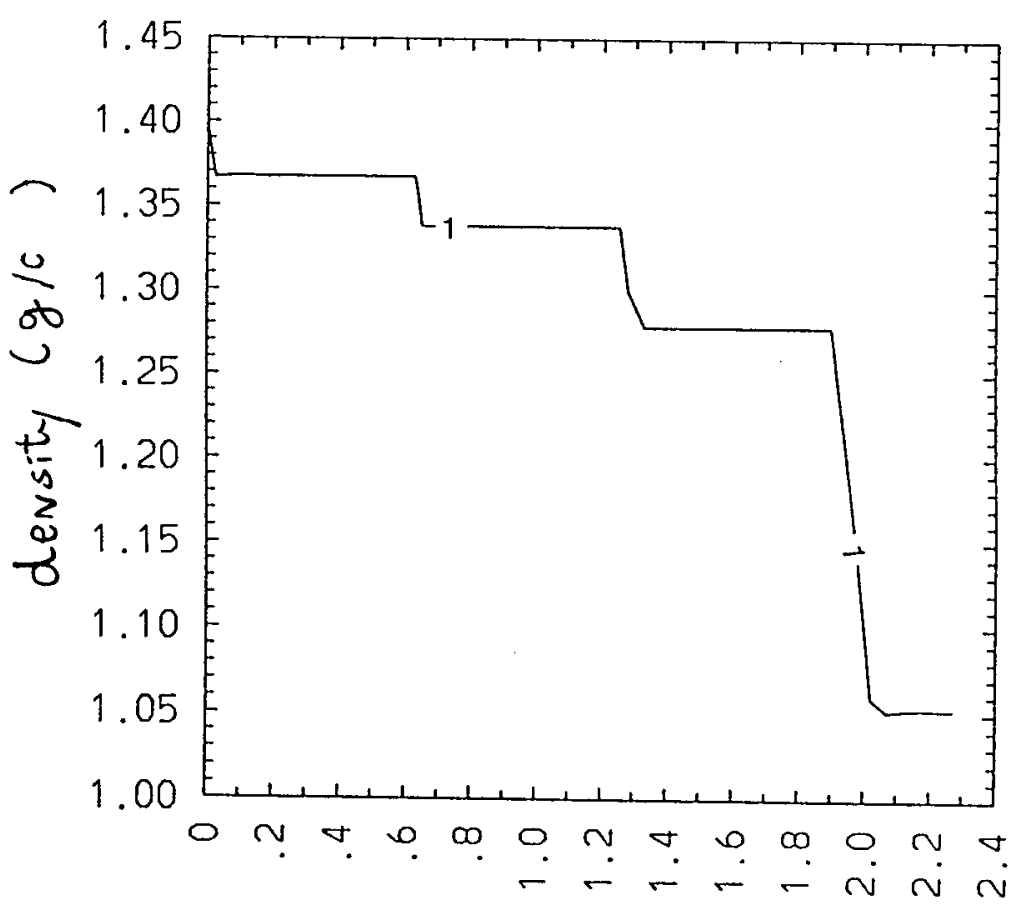

$t(\mu s)$

Fig. 3 
Mylar Pellicle

$e$-beam FWHM spot size $=3 \mathrm{~mm}$

(a)

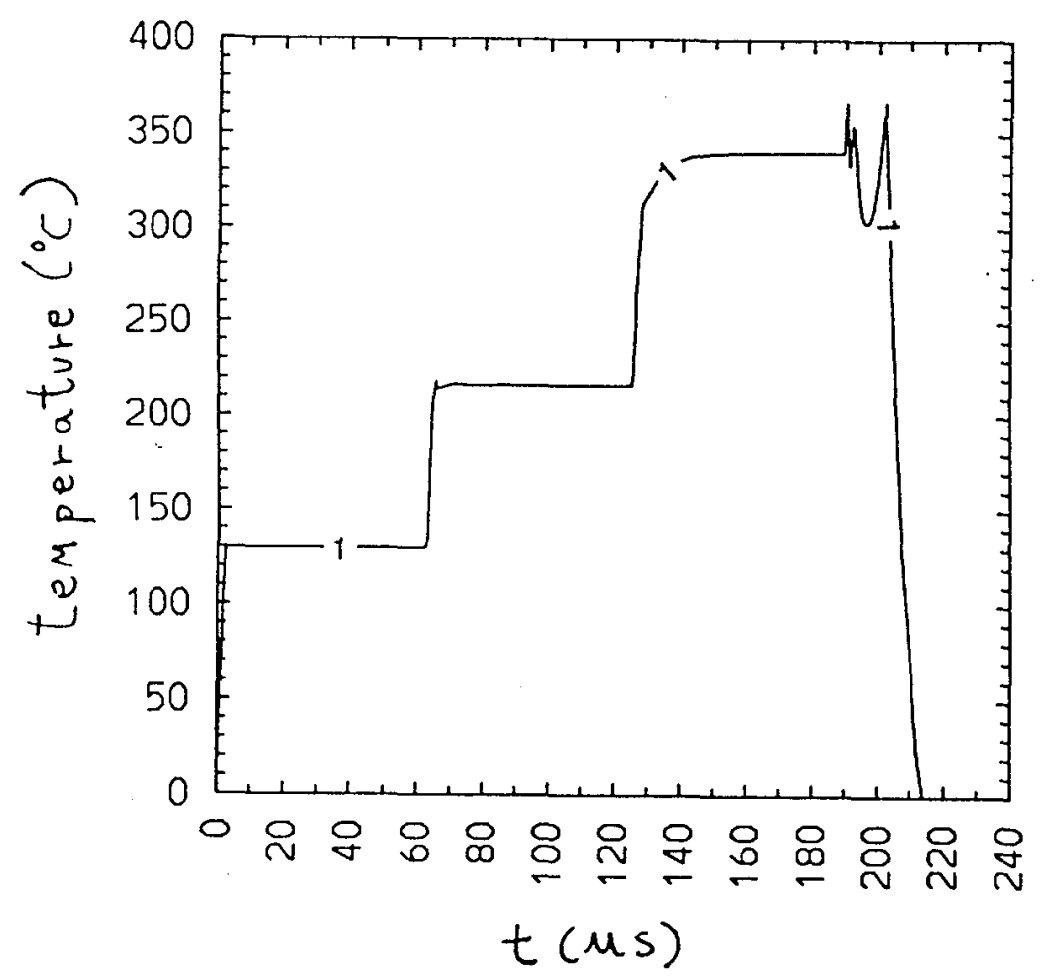

(b)

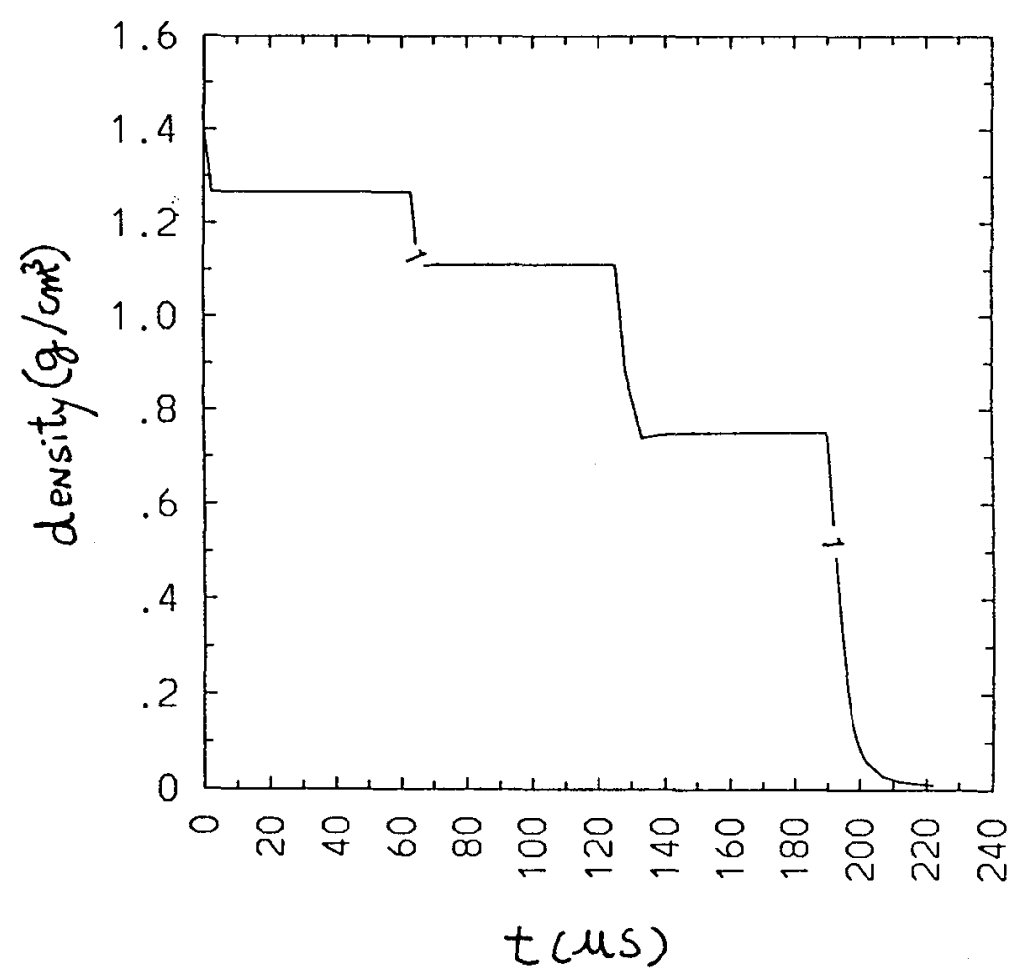

Fig. 4 


$$
\begin{aligned}
\text { Mylar Pellicle } & = \\
e \text {-beam FWHM spot size } & =3 \mathrm{~mm}
\end{aligned}
$$

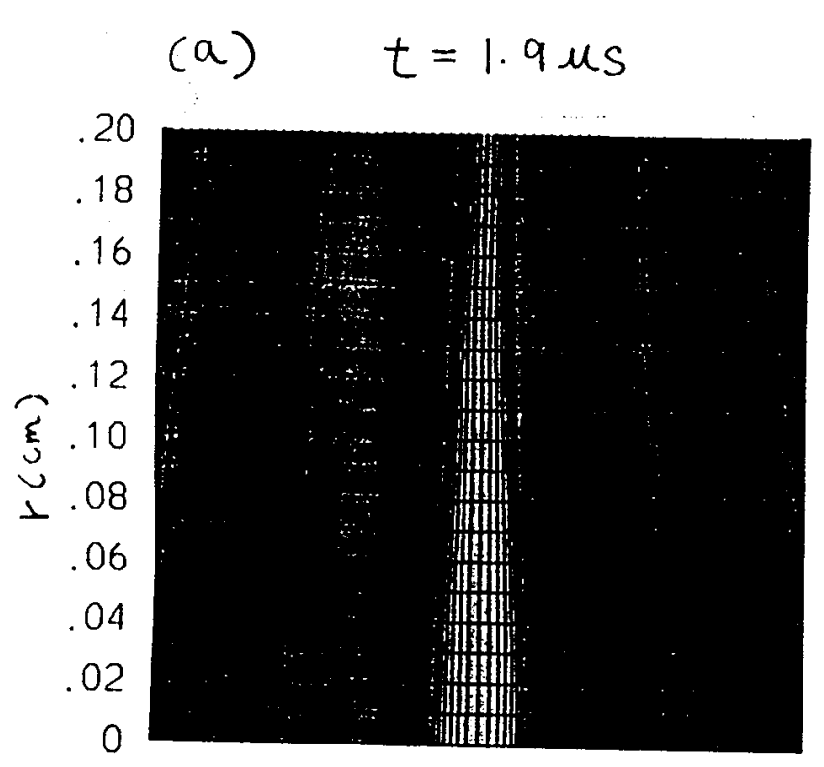

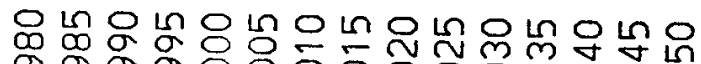

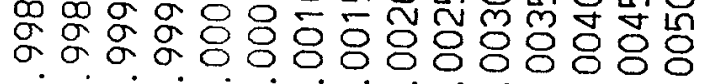

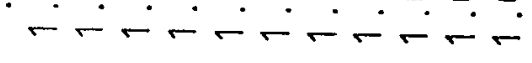

$$
z(\mathrm{~cm})
$$

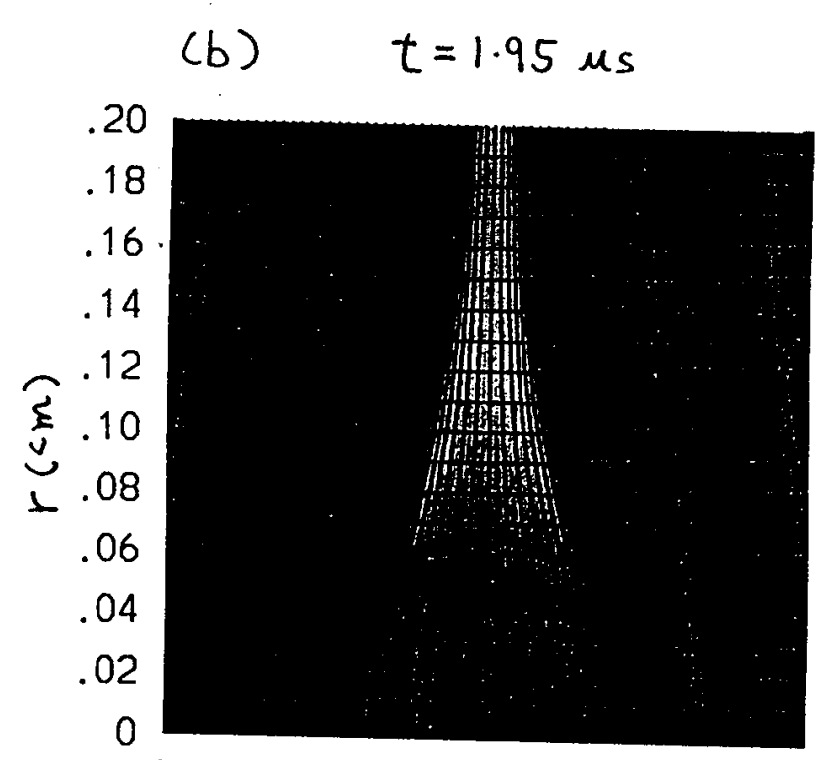

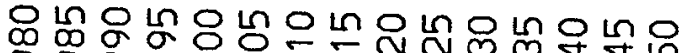
\%ু

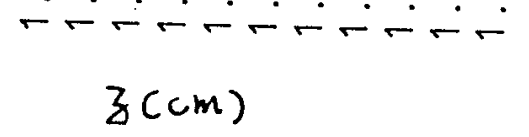

Fig. 5

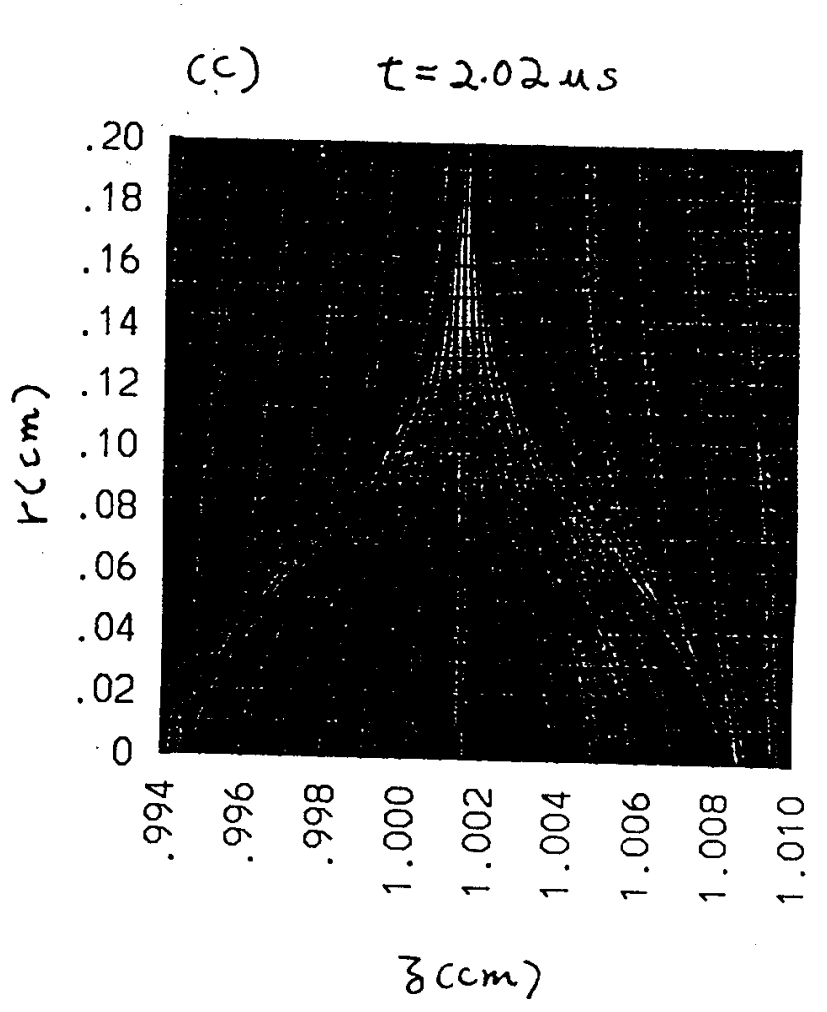


Beryllium Pellicle

e-beam FWHM spot size $=3 \mathrm{~mm}$

(a)

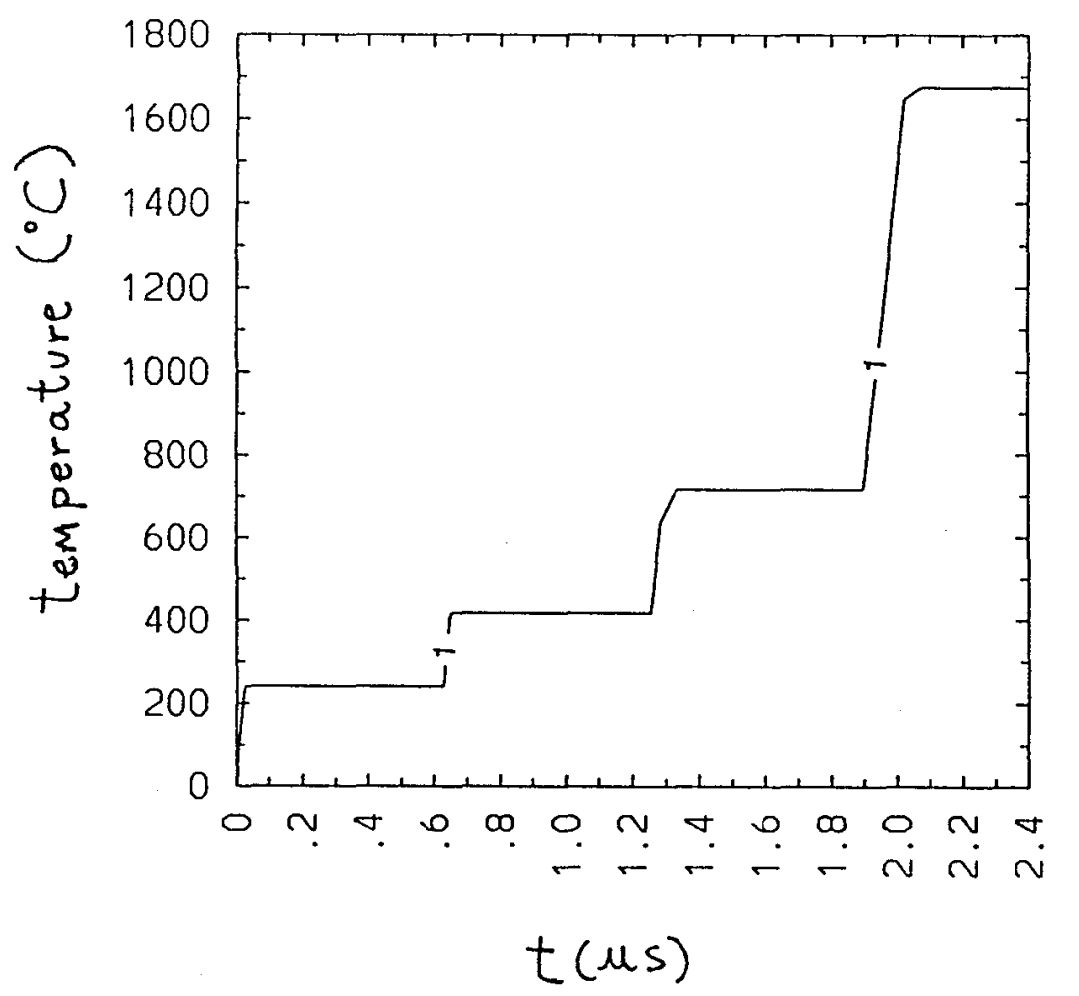

(b)

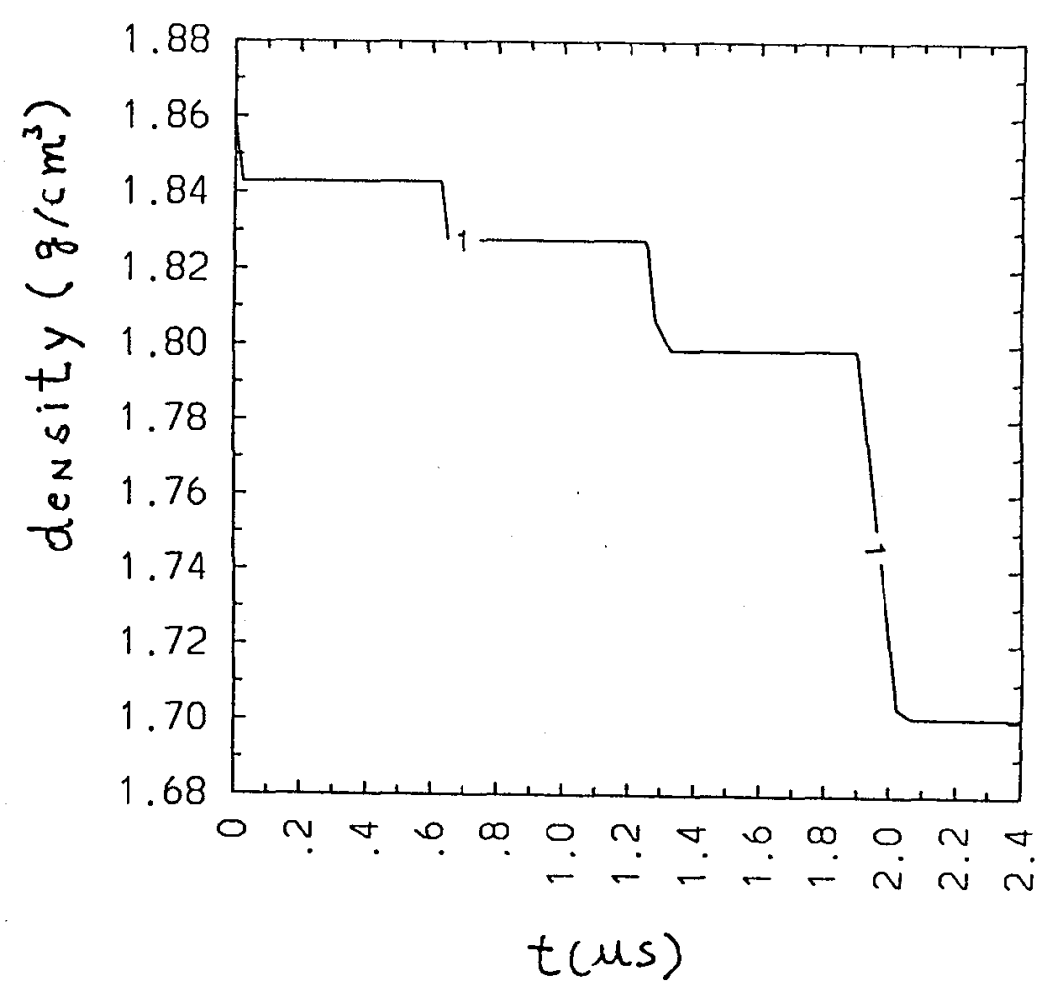

Fig. 6 


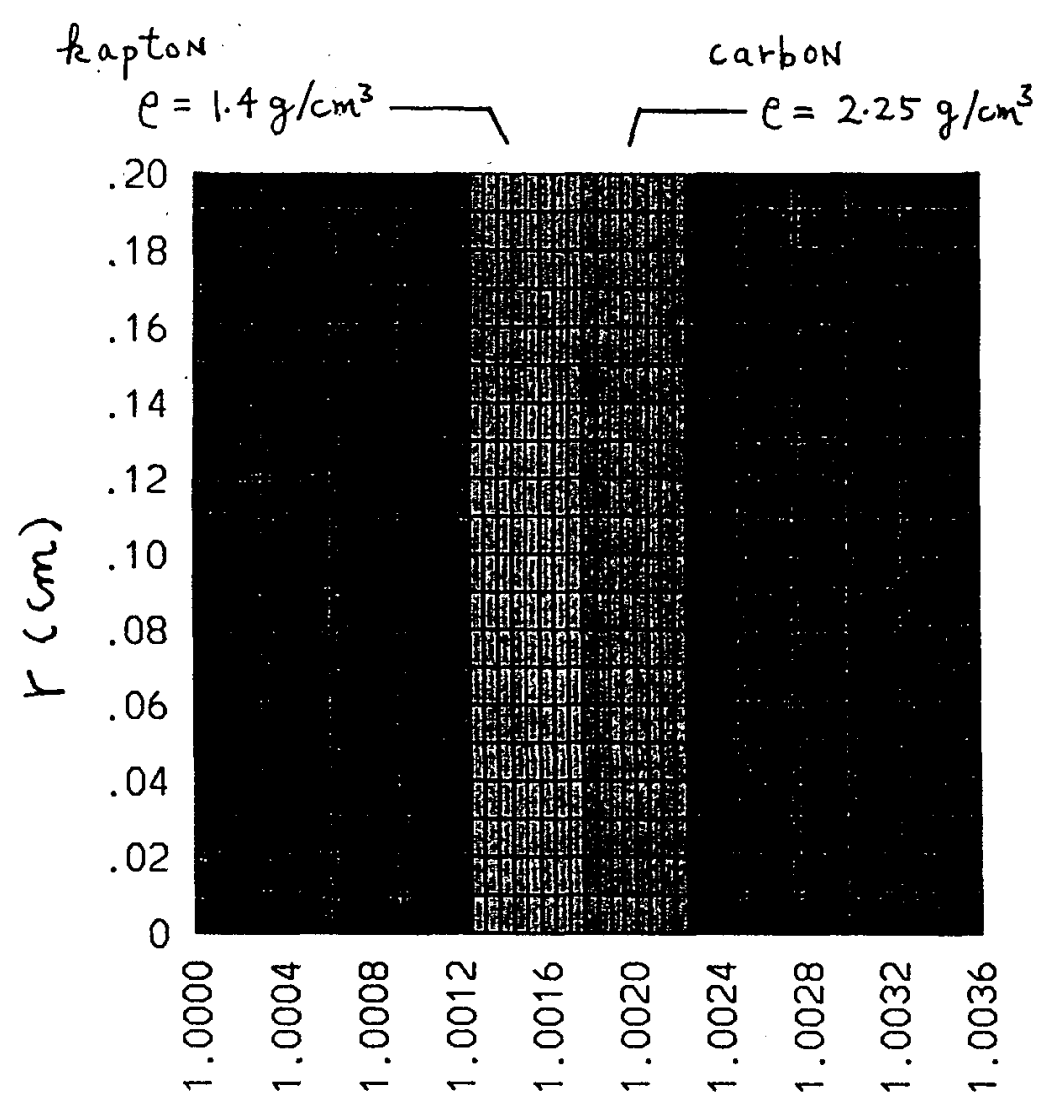

$$
z(\mathrm{~cm})
$$

Fig 7 Initial mesh configuration for

$$
\begin{gathered}
\text { kapton-carbon layered } \\
\text { pellicle }
\end{gathered}
$$




$$
\begin{aligned}
& \text { Kapton-carbon layered pellide. } \\
& \text { e-beam FWHM spot size }=3 \mathrm{~mm}
\end{aligned}
$$

(a)

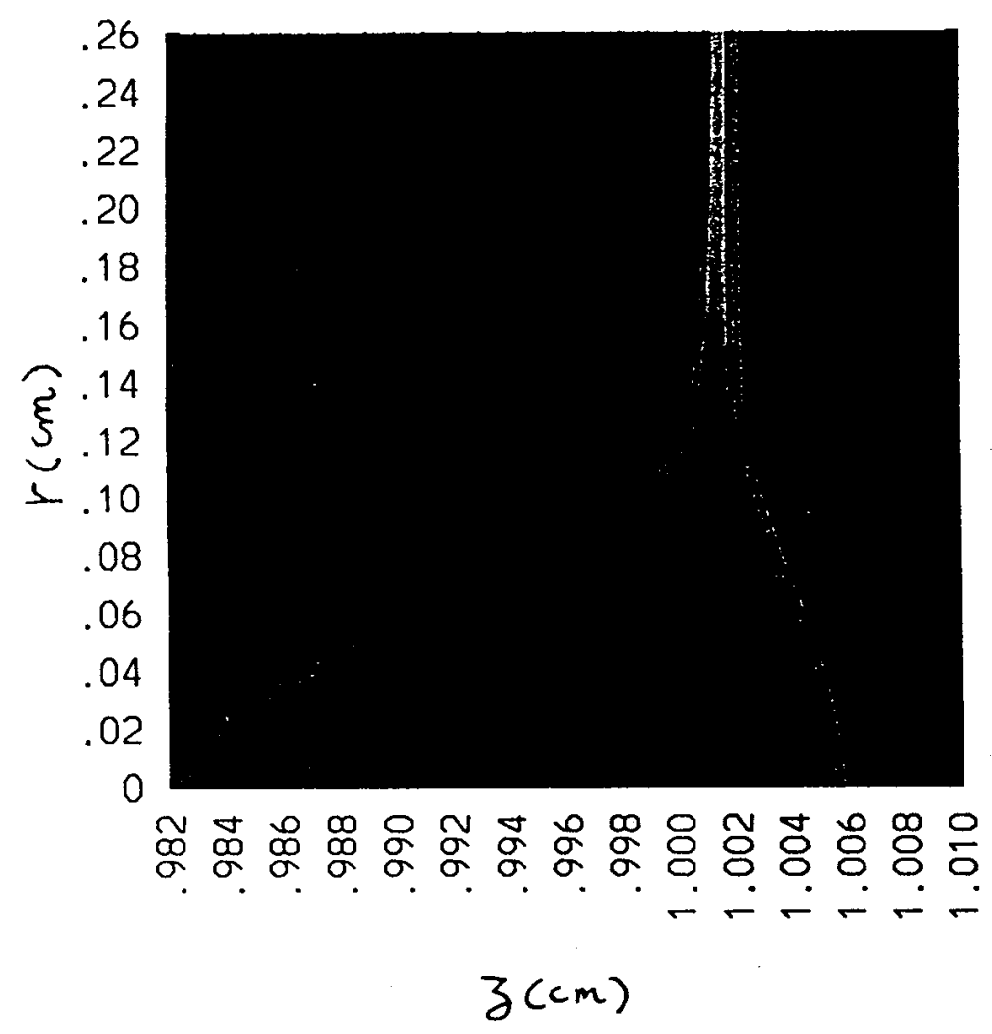

(b)

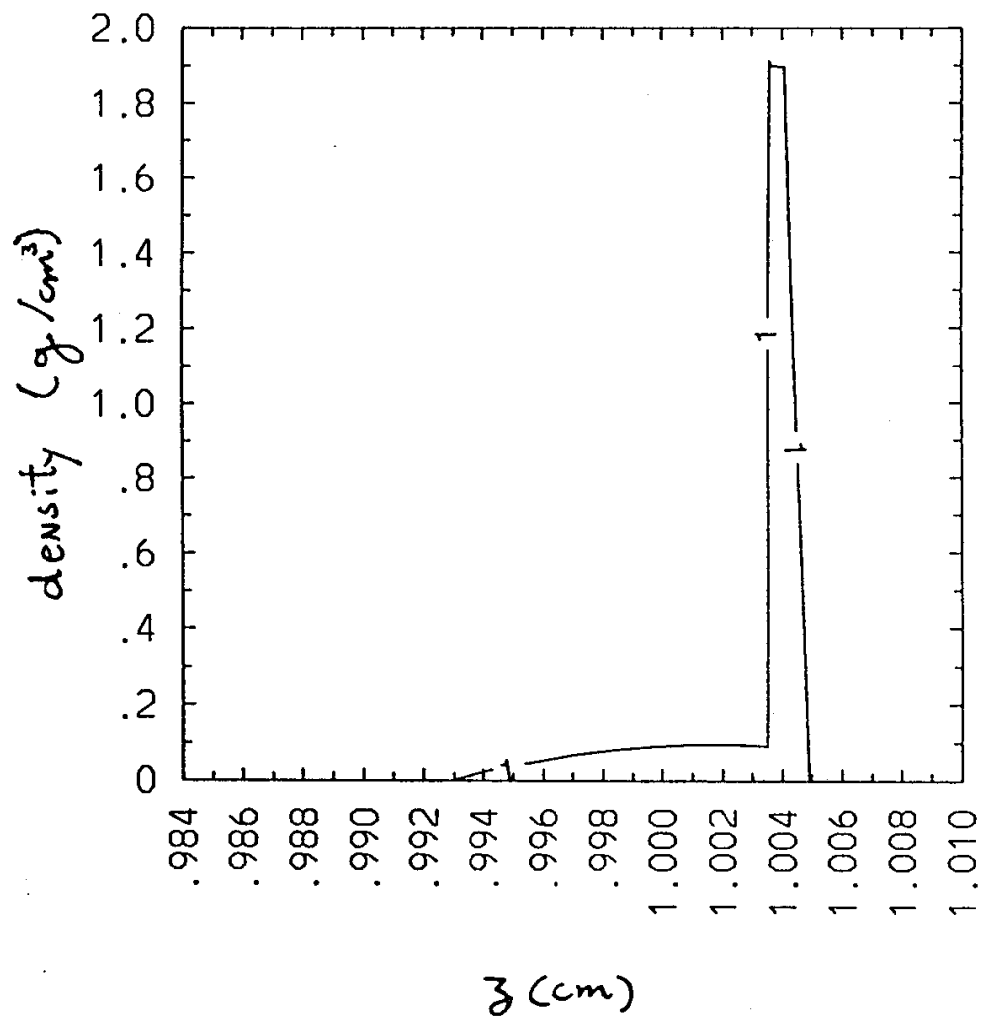

Fig. 8 
Kapton-carbon-kapton layered pellicle..

e-beam FWHM spot size $=3 \mathrm{~mm}$

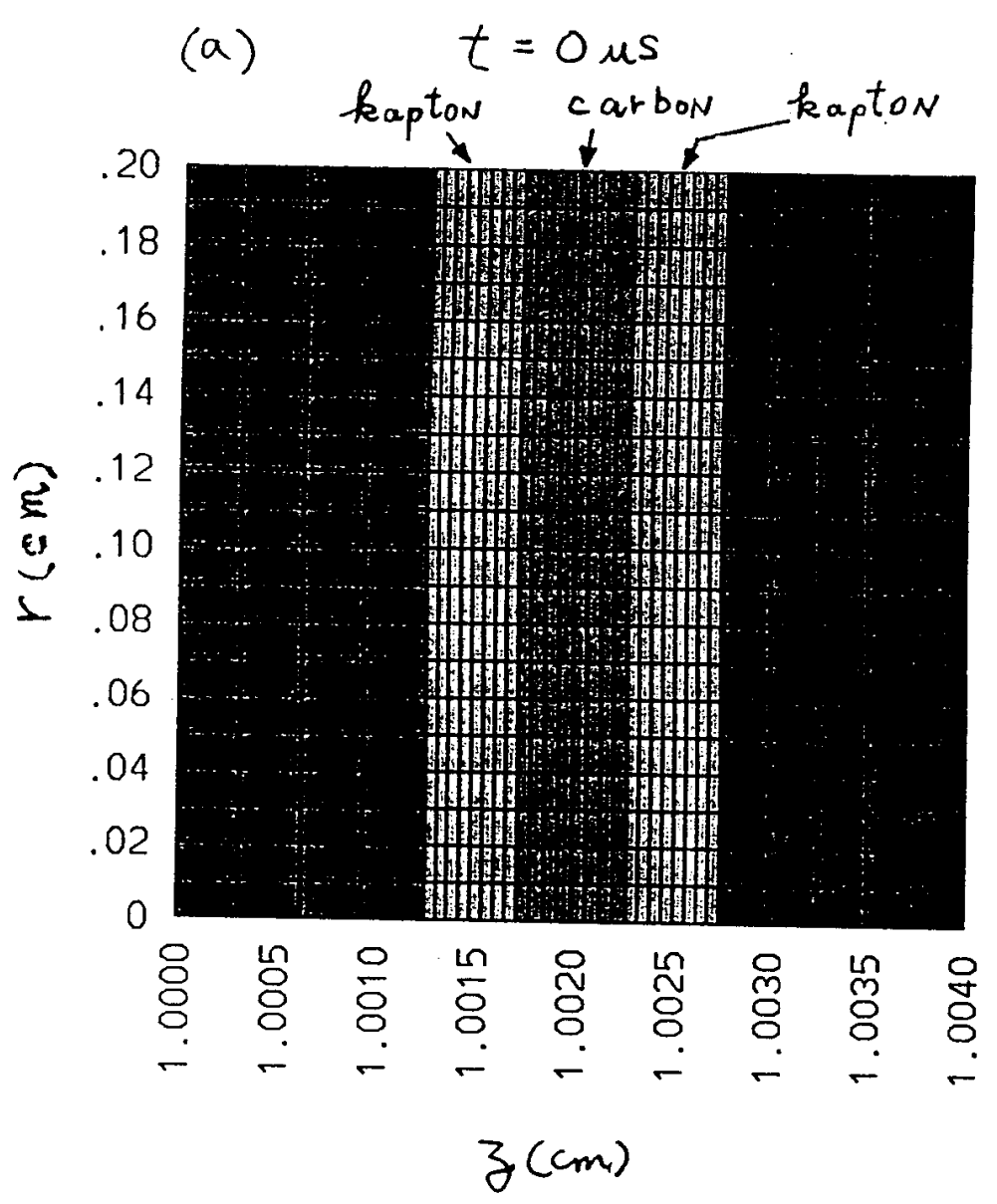

(b) $\quad t=2.02 \mu \mathrm{s}$

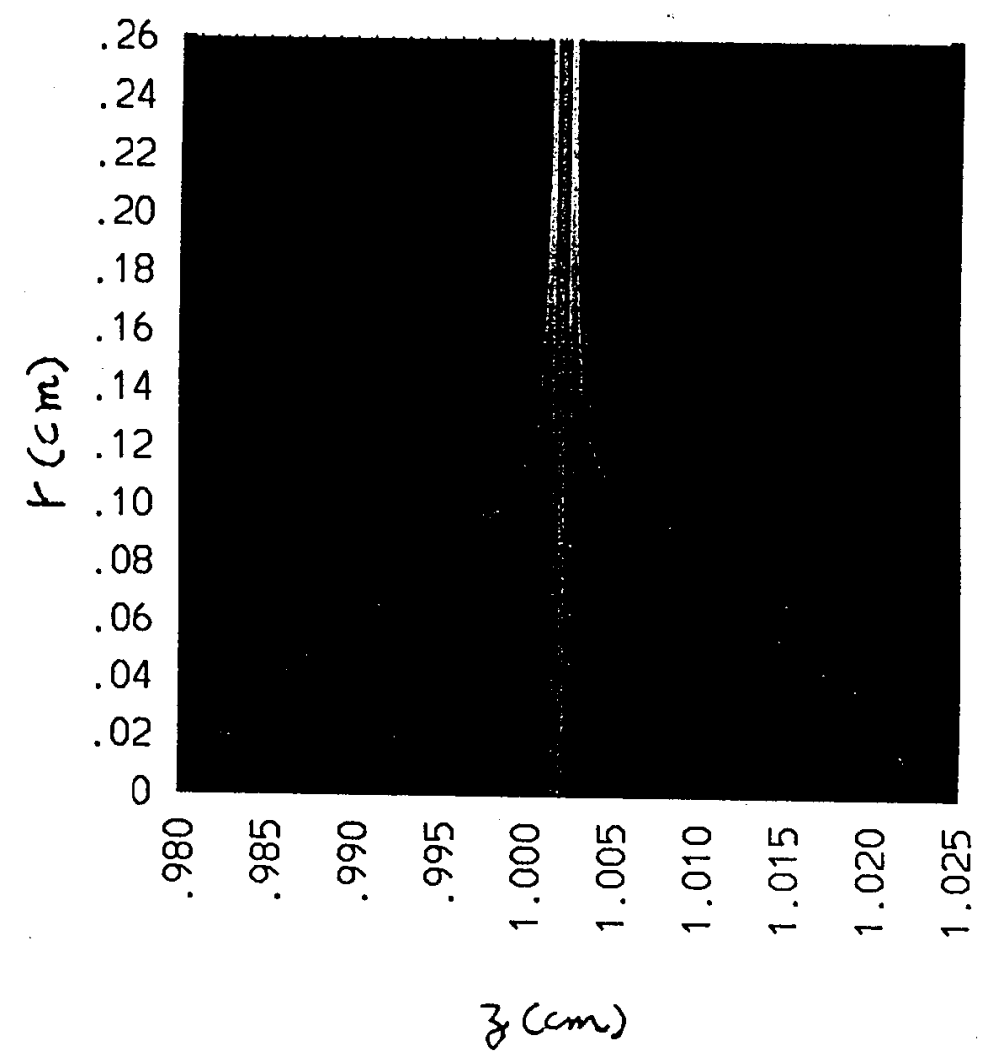

Fig. 9 
